\title{
Trends of Permanent Wetland Change in Detailed Area Plan of Dhaka
}

\author{
K.H. Razimul Karim* \\ Center for Environmental and Geographic Information Services (CEGIS), Gulshan 1, Dhaka, Bangladesh \\ *Corresponding author: razimulseye@gmail.com
}

Received August 11, 2014; Revised September 10, 2014; Accepted September 24, 2014

\begin{abstract}
Degradation of wetland creates adverse impact on natural environment, ecosystem and on drainage congestion. The situation is more alarming in case of urban areas especially for detailed area plan (DAP) of Dhaka Considering the issues, the study has taken the initiative to rapid asses the Rate of Reduction of Wetland around DAP. Available satellite images from archive have been used to compare the areal extent and statistics of degradation of wetlands. Satellite images of 1967, 1977, 1989, 1999, 2009 and 2010 have been used for preparing permanent wetland maps. For permanent wetlands, images have been selected dated between January to March as permanent wetlands can only be identified in dry season. For finding the trend of changes of permanent wetland, images from Landsat2 MSS, Landsat4 TM, Landsat5 TM (all of $80 \mathrm{~m}$ resolution) and Corona Space photo Sensor (12 $\mathrm{m}$ resolution) have been acquired. From image, wetland is delineated by unsupervised classification method to get the real situation of DAP. The study shows that due to the unplanned rapid urbanization and increased population, permanent wetland is degrading. Study reveals that Permanent wetland has been reduced from $14 \%$ to $4 \%$ during 1967 to 2010.
\end{abstract}

Keywords: degradation, satellite images, wetland, urbanization

Cite This Article: K.H. Razimul Karim, "Trends of Permanent Wetland Change in Detailed Area Plan of Dhaka.” American Journal of Water Resources, vol. 2, no. 5 (2014): 106-109. doi: 10.12691/ajwr-2-5-1.

\section{Introduction}

Wetlands cover $6 \%$ of the world's land surface and contain about $12 \%$ of the global carbon pool, playing an important role in the global carbon cycle [1]. In a world of global climate change, wetlands are considered one of the unknowns of the near future regarding element dynamics and matter fluxes [2]. The expansions of agriculture and subsequent conversion for settlement and infrastructure development along with the rising population have put immense pressure on wetlands and shrinking it alarmingly. Bangladesh is estimated to have seven to eight million hectares of wetlands in the form of permanent rivers and streams (480,000 hectares); estuarine and mangrove swamps (610,000 hectares); shallow lakes and marshes (120,000-290,000 ha); large reservoirs (90,000 ha); small ponds and tanks (150,000-180,000 ha); shrimp ponds (90,000-115,000 ha); and seasonally flooded floodplains (577, 0000 hectares) [3]. Climate change is recognized as a major threat to the survival of species and integrity of ecosystems worldwide [4]. Pressures on wetlands are likely to be mediated through changes in hydrology, direct and indirect effects of changes in temperature, as well as land use change [5]. Under currently predicted future climate scenarios, the spread of exotics will probably be enhanced, which could increase pressure on watersheds and ecosystems [6]. Moreover, climate change will make future efforts to restore and manage wetland more complex. Wetlands cover $6 \%$ of the world's land surface and contain about $12 \%$ of the global carbon pool, playing an important role in the global carbon cycle $[5,7,8]$. The expansions of agriculture and subsequent conversion for settlement and infrastructure development along with the rising population have put immense pressure on wetlands and shrinking it alarmingly.

Dhaka city is one of the largest cities in the world regarding its population density and has developed it infrastructure in unplanned way without considering the adequate drainage system as well as conservation of wetland for future. As a result the city is facing massive water logging problems frequently with moderate to heavy rainfall. The rapid urbanization and population pressure in and around Dhaka city has degraded many of the wetlands since 1960 and the process is still ongoing. However, the environment and the ecosystem of particular areas are directly interlinked with its natural wetland system and its sustainability. So the study area has been selected in and around Dhaka city to assess the extent of wetland reduction in terms of area. This study has attempted to indentify the actual extent of degradation, rate and present status of wetlands. Within limited scope of work, the main objective of the study is to: (i) determine the status of wetland reduction in Dhaka city in terms of extent of area; and (ii) Identify the causes for wetland reduction.

\section{Methodology}

\subsection{Description of Study Area}


The Detailed Area Plan (DAP) is last tier of Development Plan for Dhaka City i.e. Dhaka Metropolitan Development Plan (DMDP). DAP is developed based on detailed surveys, studies and analysis which also allowed community participation to make the planning more people oriented. Total area under DAP is around 1438 sq. km which covers the total Rajdhani Unnayan Katripakka (RAJUK) jurisdiction area. The jurisdiction of DAP Planning Area is Gazipur Pourashava to the North; Dhaleshawri River to the south; Bangshi and Dhaleshawri River to the west; and Shitalakkhya and Meghna River to the East. The study area is shown in Figure 1.

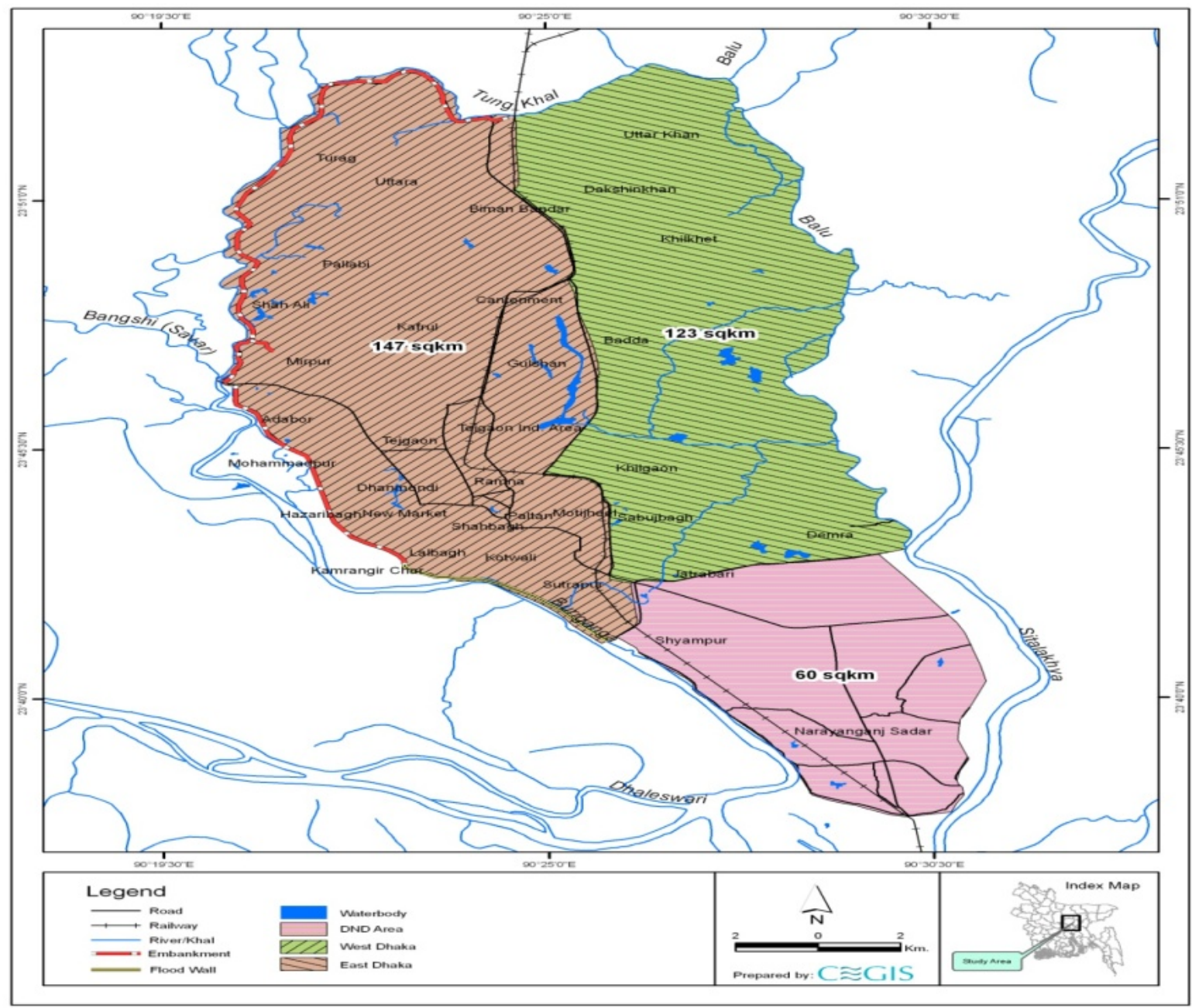

Figure 1. Location Map of the Study Area

\subsection{Satellite Image Collection}

Available multi-dated satellite images are used in this study which shown in Table 1.

Table 1. List of satellite images for permanent wetland mapping

\begin{tabular}{|c|c|c|c|}
\hline Sl No. & Sensor & Date & Resolution \\
\hline 1 & Corona Space photo & 01 March 1967 & $12 \mathrm{~m}$ \\
\hline 2 & Landsat2 MSS & 03 January 1977 & $80 \mathrm{~m}$ \\
\hline 3 & Landsat4 TM & 12 January 1989 & $30 \mathrm{~m}$ \\
\hline 4 & Landsat5 TM & 30bruary, 21March 1999 January 2010 & $30 \mathrm{~m}$ \\
\hline
\end{tabular}

For permanent wetlands, images between January to March as permanent wetland can only be identifiable in dry season images. Whilst for seasonal wetland, images between July to October have been considered. In order to avoid cloud hazard RADARSAT ScanSAR narrow beam satellite image have been used in this study. This type of image is very much useful for identifying area extent of seasonal wetlands during monsoon. However four frames of Corona Arial photographs were acquired to cover the study area. Arc GIS 9.2 and EDRAS 9.1 have been used as analysis tool in this study.

\section{Results and Discussion}

\subsection{Permanent Wetland Mapping}

Major classes like Permanent Wetlands, Settlement and urban developing area, Agriculture land/ Vegetation/ Fallow/ Bare land were extracted from the Corona Space Photo 1967 by unsupervised classification technique (Figure 2). Statistics generated from analyzed Corona Space Photo of 1 March shows that in 1967, permanent wetland covered 14\% of the area (20686 Ha), Settlement and Urban developing area covered $37 \%$ of the area (53727 Ha) and Agriculture land/ Vegetation/ Fallow/ Bare land covered $49 \%$ of the area (69667 Ha). To identify the permanent wetlands, settlement and urban developing area, agriculture land/vegetation/fallow/bare 
land of 1977 Landsat2 MSS satellite images were used (Figure 3). From the analysis it is seen that permanent wetland covered 14\% of the area (20503 Ha), Settlement and Urban developing area covered $38 \%$ of the area (54869 Ha) and Agriculture land/Vegetation/Fallow/Bare land covered $48 \%$ of the area (68708 Ha). Similarly from the analysis of images of 1989 (Figure 4) it is seen that permanent wetland reduced to $10 \%$ of the total area from $14 \%$ (as per 1967 and 1977) covering 14784 На, Settlement and Urban developing area covered 39\% of the area (55921 Ha) and Agriculture land/ Vegetation/ Fallow/ Bare land had an increase to $51 \%$ from $48 \%$ of the total area covering 73376 ha.

In 1999 (Figure 5), from the analysis it is seen that permanent wetland reduced to $4 \%$ from $10 \%$, covering $6298 \mathrm{Ha}$, Settlement and Urban developing area increased to $42 \%$ from $39 \%$ covering $60702 \mathrm{Ha}$ and Agriculture land/Vegetation/Fallow/Bare land had an increase to 54\% from 51\% covering 77080 ha. In 2010 (Figure 6), from the analysis it is seen that permanent wetland is about $4 \%$, covering $5520 \mathrm{Ha}$, Settlement and Urban developing area increased to $47 \%$ from $42 \%$ covering $68144 \mathrm{Ha}$ and Agriculture land/Vegetation/Fallow/Bare land had a decrease of $49 \%$ from 54\% covering 70417 Ha.

\subsection{Analysis of Permanent Wetland Degradation}

A comparison has been made based on the area statistics that were extracted from the Permanent Wetlands maps of different years. Figure 7 shows the statistical comparison between different years for the Permanent Wetland degradation. In 1967, about 20686 hectares of total 144080 hectares area were Permanent Wetlands. Settlement and Urban developing area was 69667 hectares and Agriculture land/Vegetation/Fallow/Bare land cover was about 69667 hectares. In 1977, there was no significant change in wet land in comparison to 1967. However, Agriculture land/Vegetation/Fallow/Bare land decreased moderately. On the other hand, from 1989 to 2010 wetland sharply decreased (from 14784 to 5520 hectares) mainly due to settlement and urban developing area expansion but Agriculture land contribute a little.

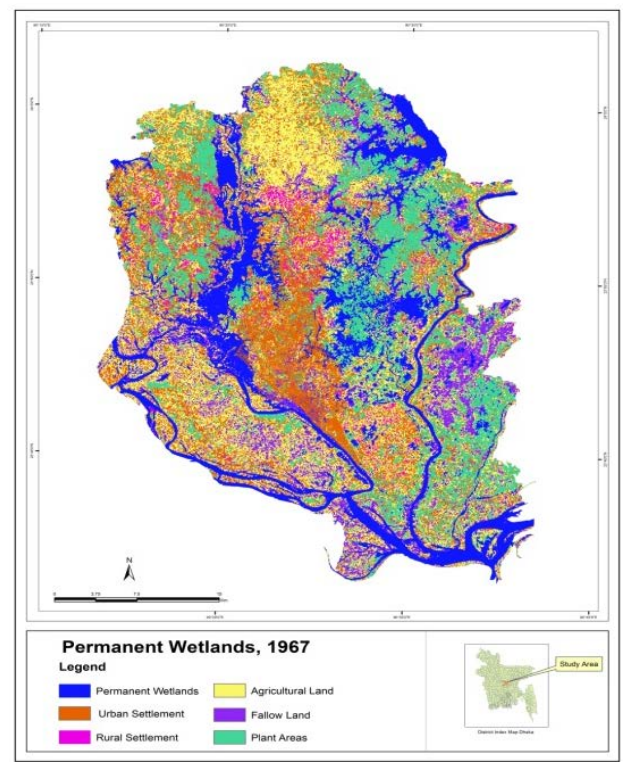

Figure 2. Permanent wetlands of 1967 derived from Corona Space Photo

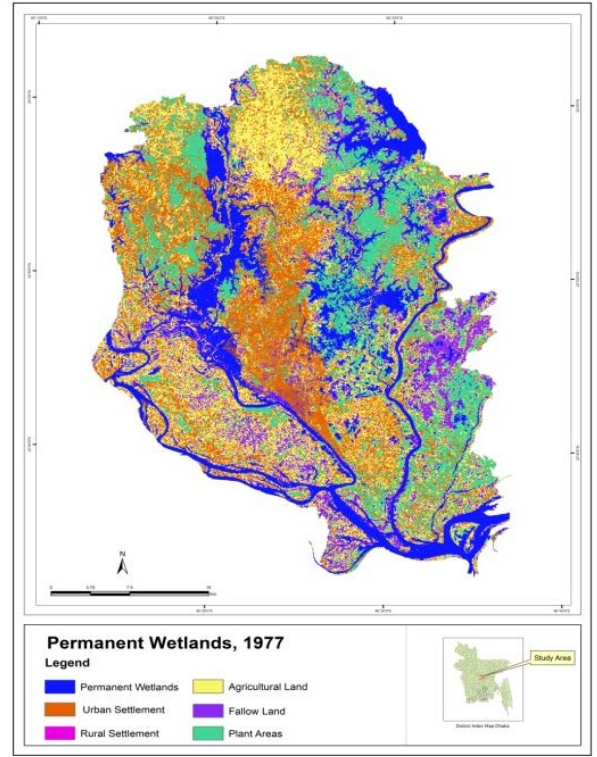

Figure 3. Permanent wetlands of 1977 derived from Landsat2 MSS satellite images

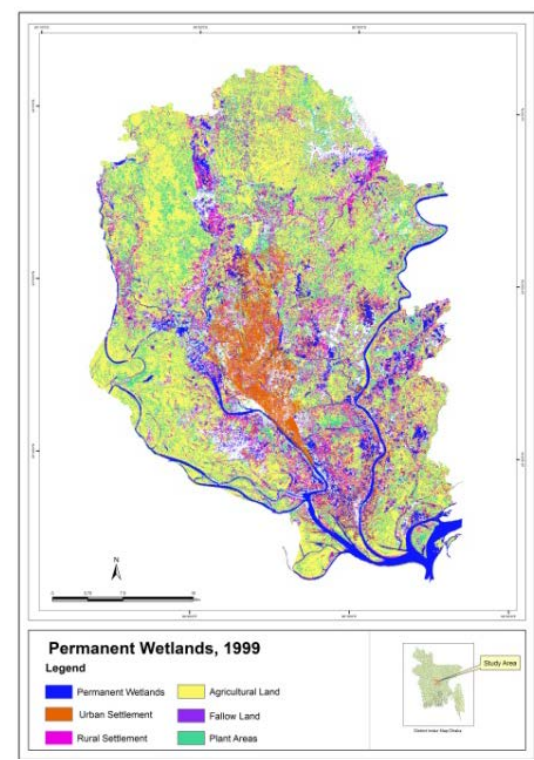

Figure 4. Permanent wetlands of 1989 derived from Landsat4 TM

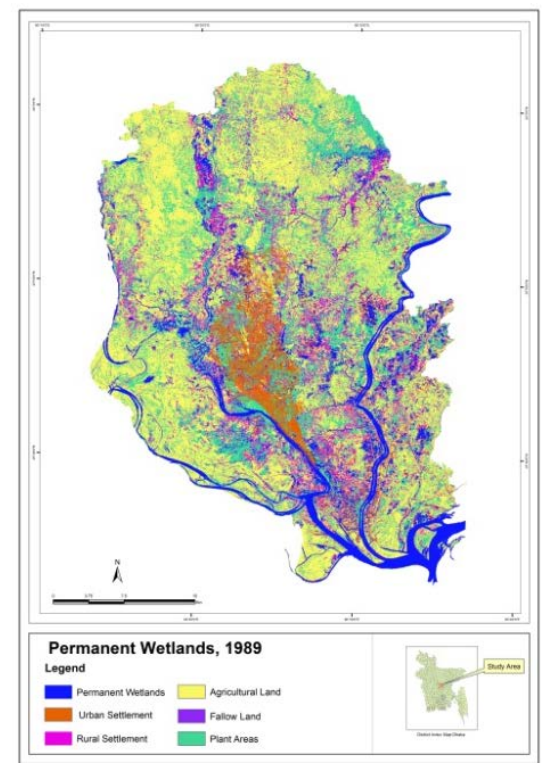

Figure 5. Permanent wetlands of 1999 derived from Landsat5 TM 


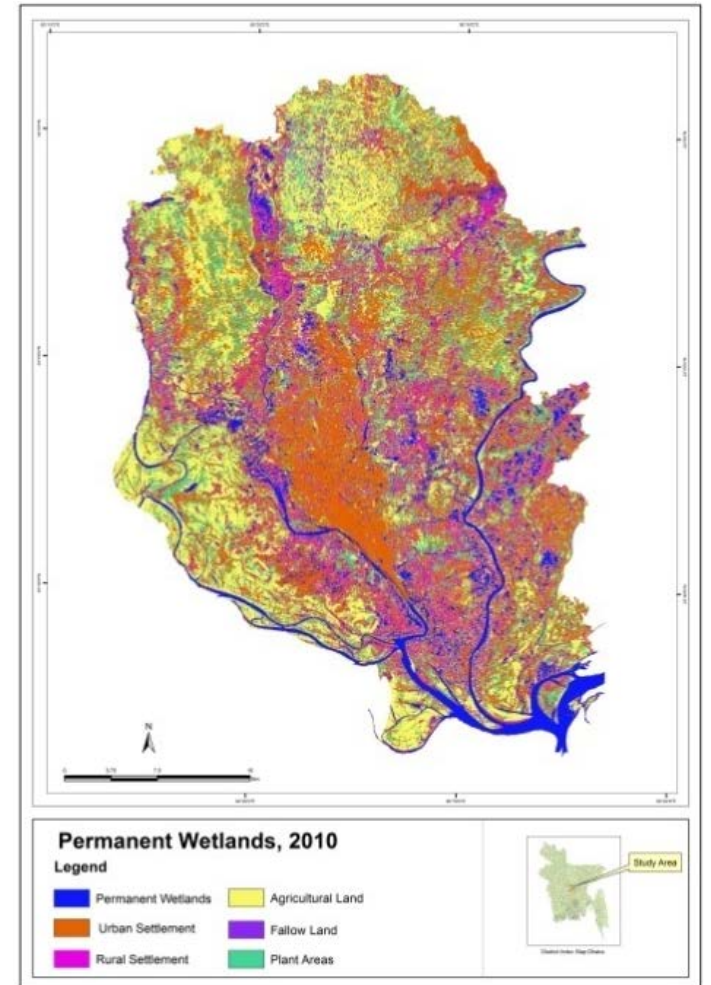

Figure 6. Permanent wetlands of 2010 derived from Landsat5 TM

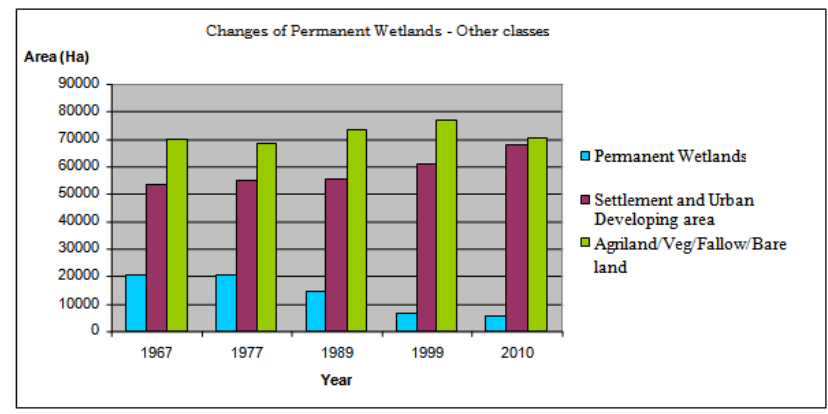

Figure 7. Scenario of how Permanent Wetlands degraded by other classes from 1967-2010

\section{Conclusion}

Rapid urbanization with incremental population pressure has been forced for expanding the Dhaka city urban area and consequently it has been created tremendous pressure on invaluable wetlands around the city. The study indicates that permanent wetlands are degrading. The wetlands are continuously transforming into settlements, and other commercial purposes, which is neither sustainable nor environmental friendly. It is reveled from the study that the Permanent wetlands reduced from $14 \%$ to $4 \%$ from 1967 to 2010 . The rate of permanent wetland reduction is $353 \mathrm{ha} /$ year.

\section{References}

[1] Ferrati R, Canziani GA, and D.R. Moreno (2005). Estero dellbera: hydro-meteorological and hydrological characterization. Ecol Model, 186: 3-15.

[2] Paul S, Jusel K, and C Alewell (2006). Reduction processes in forest wetlands: tracking down heterogeneity of source/link functions with a combination of methods. Soil Bio Biochem, 38: 1028-1039.

[3] Nishat A, Hossain Z, Roy M K and. Karim A (eds.) 1993. Freshwater Wetlands in Bangladesh-Issues and Approaches for Management. IUCN, 1993.

[4] Hulme PE 2005. Adapting to climate change: is there scope for ecological management in the face of a global threat? Journal of Applied EcoIogy volume 42: page 784-794.

[5] Ferrati R, Canziani GA, Moreno DR (2005) Estero dellbera: hydro-meteorological and hydrological characterization. Ecol Model 186:3-15.

[6] Root TL, Price JT, Hall KR, Schneider SH, Rosenzweig C, Pounds JA 2003. Fingerprints of global warming on wild animals and plants., Nature, page: 421: 57-60.

[7] IPCC (International Panel on Climate Change) 1996. Climate change 1996-impacts, adaptations and mitigation of climate change: scientific technical analysis. Contribution of working group II to the second assessment report of the IPCe. Cambridge University Press, Cambridge.

[8] IPCC (International Panel on Climate Change) 1998. The regional impacts of climate change: an assessment of vulnerability. In: Watson RT, Zinyowera MC, Moss RH (eds) A special report of IPCC working group II. Cambridge University Press, Cambridge. 